\title{
Development and research of aerodynamic stand
}

\author{
Davydov Y.F. \\ Department of Engineering \\ D. Serikbayev East Kazakhstan state technical university \\ Ust-Kamenogorsk, Kazakhstan \\ Asangaliev E.A. \\ Department of Engineering \\ D. Serikbayev East Kazakhstan state technical university \\ Ust-Kamenogorsk, Kazakhstan
}

\author{
Dudkin M.V \\ Department of Engineering \\ D. Serikbayev East Kazakhstan state technical university \\ Ust-Kamenogorsk, Kazakhstan \\ Erulanova A.E. \\ Department of Information Technologies \\ D. Serikbayev East Kazakhstan state technical university \\ Ust-Kamenogorsk, Kazakhstan \\ A_Erulanova@BK.ru
}

\author{
Daurenov A.D \\ ITPSO \\ D. Serikbayev East Kazakhstan state technical university \\ Ust-Kamenogorsk, Kazakhstan
}

\begin{abstract}
- the hydrodynamic processes occurring in devices and the influence of various factors on the flow regime were analyzed. A working section of the aerodynamic stand was developed and models that make it possible to investigate the flow by measuring the pressures, velocities, and resistance of the device were created.
\end{abstract}

Keywords - aerodynamic stand; swirler; swirl device; blower; hydraulic resistance; air consumption; measuring equipment.

\section{INTRODUCTION}

It is necessary to process the sulfur dioxide gas to produce sulfuric acid at the enterprises of nonferrous metallurgy, including zinc during pyro metallurgical processing of sulphide raw materials. This redistribution is an integral part of the technology and requires solving the issues of production optimization through technology and environmental regulations. The contribution of sulfuric acid factories to the pollution of the industrialized regions is associated with the content of toxic compounds of sulfuric and sulfur dioxide and sulfuric acid vapors in emissions.

Polydisperse two-phase flows arising in traditional sulfuric acid production technology are non-stationary, which makes it difficult to conduct operational quality control of the technological process of its production. To overcome the negative factors, it becomes necessary to develop optimal, from the hydraulic point of view, piping systems with minimum hydraulic resistance, creating monodisperse, predictable continuously and reliably controlled two-phase flows.

A very urgent task is that of creating a single automated system that allows us to continuously assess the state of the devices in the sulfuric acid production complex.

\section{AERODYNAMIC STAND AND MODELS}

An aerodynamic stand for the study of a two-phase flow and subsequent continuous measurement of its main parameters was created. The aerodynamic stand was created for carrying out experimental studies .The stand allows one to measure the hydraulic resistance and to study the structure of the flow in the working area. The design of the stand makes it possible to study the flow parameters both in the immediate vicinity of the swirler and at a considerable distance from it; allows you to install different types of swirl devices. The stand consists of electric power equipment, which sets the air in motion, and the aerodynamic part forming the flow necessary for structure experiments. The stand operates on an open circuit in the pressure regime (Figure 1).

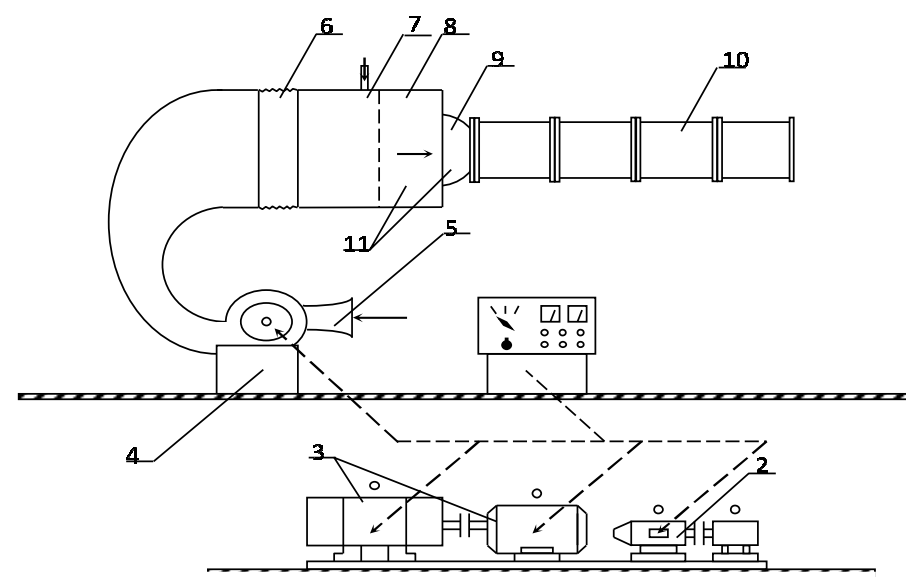

Fig. 1. A diagram of aerodynamic stand (1-control panel; 2 - electromotive amplifier; 3 - converter unit "engine-generator"; 4 - electric motor and blower; 5 - air collecter; 6 - a flexible branch pipe; 7 - pressure chamber; 8 - grids; 9 radius input (confuser); 10 - separator model; 11 - pressure sampling.) 
The movement of air through the pipeline is provided by a centrifugal blower driven by an electric motor 4 . The air is taken from the laboratory room by an air blower through an air collector 5 , protected by a metal mesh, which ensures the safe operation of the blower. Then, through the bell and the flexible nozzle 6 , air enters the pressure chamber 7 , in which the grids 8 are installed to stabilize the flow. From the pressure chamber 7 air through the confuser 9 enters the working section of the model. After passing through the working area, air enters the laboratory room. In the pressure chamber 7 and in the confuser, drainage holes $11(\mathrm{~d}=0.8 \mathrm{~mm})$ are made, necessary for measuring the pressure and calculating the air flow. A liquid drop phase is fed through the nozzle 12. The air flow in the pipeline is controlled by changing the rotational speed of the blower impeller. The drive of this device is a direct current motor $\Pi 51$ with a power of $\mathrm{N}=6 \mathrm{~kW}$ and a nominal speed of rotation $\mathrm{n}=1500 \mathrm{rpm}$. For its power supply, a converter unit "engine-generator" 3 is used: an induction motor of type AO262-6 with a power of $13 \mathrm{~kW}$ and a direct current generator $\Pi \mathrm{H}-100$ with a power of $9.5 \mathrm{~kW}$. In the excitation winding of the generator when the blower operation mode is set to stabilize the rotation speed of the driving motor 4 , a feedback system is created using the EMU-502 electric machine amplifier, which maintains a constant output voltage of the generator. To prevent vibration transmission, the blower 4 is separated from the pressure chamber 7 by a nozzle 6 made of elastic rubber. The amount of air flow is adjusted in a wide range by changing the position of the handle of the latter on the control panel of the stand 1. The stand is turned on and off also from the control panel 1. The experimental model of the separator-accumulator consisted of two coaxial cylindrical pipelines. The internal perforated pipeline with a diameter of $260 \mathrm{~mm}$ has a hole diameter of $4 \mathrm{~mm}(15,300$ holes, a porosity of $49 \%$ ). The length of the perforated pipeline is $1200 \mathrm{~mm}$, an impermeable cap is installed at the end section. In the initial section, it is interfaced with a confusional transition by a cylindrical metal insert.

The outer pipeline consists of four bolted cylindrical sections. In the initial section, it is connected to the transition confuser by means of fixing. Installation and adjustment of the position of a perforated pipeline inside the outer is produced by twelve positioning pins located in three sections through 90 $\circ$ This design allows for a uniform annular gap over the entire length of the working area. Docking sections of the external pipeline is carried out by flanges with centering grooves such as a spike-groove, which exclude the possibility of displacement and the formation of a ledge at the junction. The total length of the external pipeline is $1500 \mathrm{~mm}$, diameter 300 mm (Figure 2).

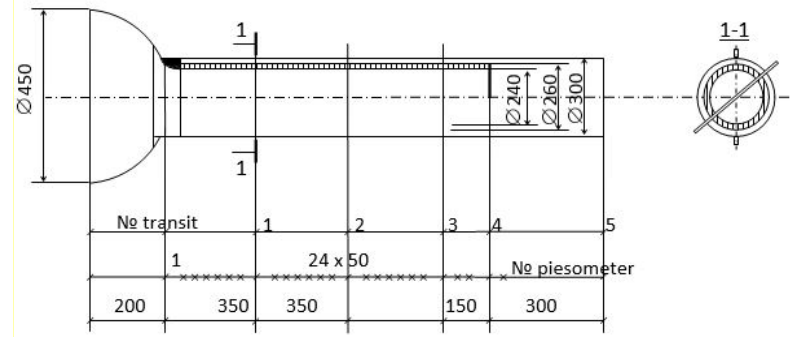

Fig. 2. A diagram of the experimental model of a separator
The numbering of models $1,2,3,4$ is made depending on the type of swirler installed in the cylindrical (steel) insert located in the transition confuser. Index 1 corresponds to a model without a swirler device. Swirlers of three types are used in this experiment:

a) with the swirling of the flow along the wall of the perforated pipeline, the inner diameter of the swirler is 210 $\mathrm{mm}$, the outer diameter is $232 \mathrm{~mm}$, the blade height is $33 \mathrm{~mm}$, the number of blades is 30 ;

b) axial-scapular with a full swirl of the flow, variable angle of attack. The diameter of the inner body is $150 \mathrm{~mm}$, the height of the blades is $53 \mathrm{~mm}$ :

c) axial-vortex swirler with a full flow swirl, variable flow angle. The internal body diameter is $76 \mathrm{~mm}$, the blade height is $91 \mathrm{~mm}$.

The indexing of test models with twisting devices is carried out in such a way that the index 4 corresponds to a swirler of type a), an index 2 corresponds to a swirler of type b) an index 3 corresponds to a swirler of type c).

The working environment of the aerodynamic stand is the air taken from the laboratory premises. The experiments were carried out at an air temperature ranging from $18^{\circ} \mathrm{C}$ to $24^{\circ} \mathrm{C}$ and atmospheric pressure from 723 to $765 \mathrm{~mm} \mathrm{Hg}$. A slight relative change in temperature and air pressure made it possible to use for calculation of its density the conventional linear approximation [1]:

$$
\rho_{\text {air }}=1.125 \frac{288}{273+t} \frac{P_{a}}{760}
$$

where

$\mathrm{t}$ - the temperature in degrees Celsius;

$\mathrm{Pa}$ - the pressure in millimeters of mercury.

Dynamic viscosity of air was calculated by the formula of Kopa and Hartree:

$$
\mu=0.115 \cdot 10^{-6} \cdot(t+273)^{8 / 9} .
$$

In addition, the kinematic viscosity, needed to calculate the Reynolds number, was calculated through the dynamic:

$$
v=\mu / \rho_{\text {air }}
$$

The air temperature was measured by a mercury thermometer with a division price of $1 \mathrm{~K}$. The temperature of the air in the laboratory room was measured. The control measurements of the air temperature at the entrance to the aerodynamic stand and at the outlet from the outlet pipeline showed the same values, which makes it possible to assume that the flow is isothermal. Atmospheric pressure was measured by an aneroid barometer having a scale rating of 1 $\mathrm{mm} \mathrm{Hg}$. The experiments were performed at mean velocities up to $28 \mathrm{~m} / \mathrm{s}$, which corresponds to the Mach number $\mathrm{M}=$ 0.08 . Since the Mach number enters into the expression for the squeezed liquid loss in the square [2], the correction for the compressibility would not exceed 0.0034, and in most experiments it would be even smaller, so the compressibility of the air during the processing of the experimental data was not taken into account. To measure the pressure on the walls of the pipeline, drain holes were used for four measuring 
sections with a diameter of $0.5 \mathrm{~mm}$ and a device for fixing the union (Figure 2).

\section{RESISTANCE MEASUREMENT}

The hydraulic resistance of the models was calculated from the differential pressure in the working area. The pressure drop in the working area was measured with a differential MMH240 micro manometer (the measurement error is 0.05) filled with ethyl alcohol, as well as an MKB-250 micromanometer with an accuracy class of 0.02 . The pressure drop was calculated using the following formula:

$$
P_{1}-P_{0}=m \cdot g \cdot A \cdot \rho_{a l c}
$$

$\mathrm{m}$ - sine of the angle of inclination micro manometer tube; $\mathrm{g}$ - acceleration of gravity, $9.81 \mathrm{~m} / \mathrm{s}^{2}$;

$\rho$ alc - alcohol density, $\mathrm{kg} / \mathrm{m}^{3}$;

A - reading on the micromanometer scale, $\mathrm{m}$.

Pressures $\mathrm{P}_{1}$ and $\mathrm{P}_{0}$ were taken at the initial and final sections of the model under study. The Reynolds number was determined from the corresponding average flow rate $V_{i}$ and the diameter $d_{i}$ or $\delta$ - the width of the gap between the inner and outer pipelines. To determine the coefficients of resistance and the Reynolds number for known geometric dimensions of the flow part, the flow Q was measured, along which the average velocities and the velocity head in any section were calculated:

$$
\zeta=\zeta_{g e n} \cdot \zeta_{T} ; \zeta_{g e n}=\frac{P_{1}-P_{0}}{1 / 2 \cdot \rho \cdot V_{0}^{2}}
$$

where

$\zeta \mathrm{t}$ - coefficient of friction in the area between the measurement sections.

The error in measuring the resistance coefficient of the working section of the model is determined by the formula:

$$
\zeta_{g e n}=\frac{m \cdot g \cdot A \cdot \rho_{a l c}}{1 / 2 \cdot \rho \cdot V_{0}^{2}}
$$

Taking the relative error of the sine of the slope of the tube of the manometer $\delta_{\text {alc }}$ equal to 0.001 , we find that $\zeta_{\text {gen }}$ varies from 1.94 to $0.77 \%$. The value of $\zeta_{\mathrm{T}}$ for different models ranged from $\zeta_{\text {gen }}$ from 0.03 to 0.3 . The error in measuring the local resistance coefficient of the model $\zeta$ lies in the interval from 2.00 to $1.01 \%$.

\section{MEASUREMENT OF PRESSURE AND VELOCITIES}

There are four dimensional sections (Figure 2) to measure pressures and velocities in the flow. The measurements were carried out in three ways: a cylindrical tube with a diameter of $5 \mathrm{~mm}$ (hole $\mathrm{d}=0.8 \mathrm{~mm}$ ), and then in the most characteristic sections the values of the averaged velocity were checked by a ball probe and a thermo anemometer.

The results obtained were compared with each other and showed the correctness of the use of cylindrical tubes $[4,5,6,7$ ]. The movement of the cylindrical tube along the section of the model (in the radial direction) was carried out by the coordinator of the design- LPI, which ensures a displacement accuracy of $0.5 \mathrm{~mm}$. The pressure in the receiving hole and in the drainage holes on the model wall was recorded with differential micro manometers of the MMN-240 type, filled with ethyl alcohol. When calculating the local averaged velocities, the velocity head for each point was assumed equal to the difference in the total head measured by the cylindrical tube and the static head on the outer wall in the same section. The method of measurement is based on the rotation of the tube with the aid of a $180^{\circ}$ coordinator around its axis and the measurement by the manometer of the values along the gas flow and in the opposite direction. To calculate $\Delta \mathrm{P}$, it is necessary to know the coefficient of this probe (tube). The calibration was carried out as follows (8). With the assistance of the coordinator, a tube with a lateral hole in the pipeline was rotated about $360^{\circ}$ around its axis at an interval of $1^{\circ}$, and the manometer readings were taken for each value. Then, according to the obtained data, a calibration curve was constructed (Fig. 3).

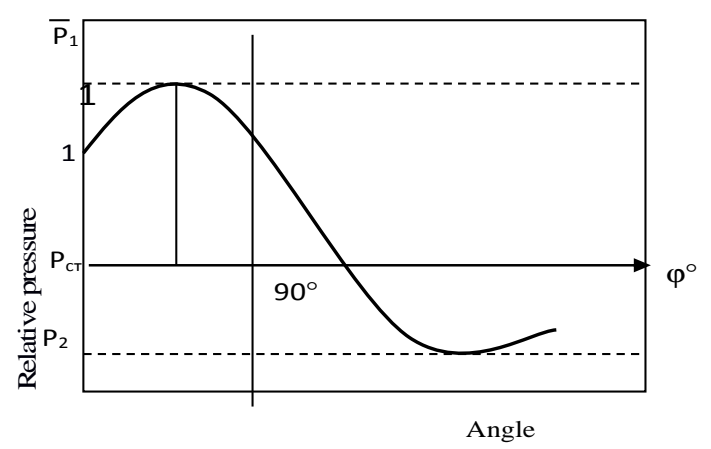

Fig.3. The calibration curve for a cylindrical tube with a lateral hole

The ball probe (Figure 4) has a spherical head $\mathrm{d}=5 \mathrm{~mm}$ with five holes $\mathrm{d}=0.3 \mathrm{~mm}$, drilled in two mutually perpendicular planes. The angle between the axis of the central and each of the side openings is $40^{\circ}$. The hole is connected by thin capillaries passing inside the holder with the fittings located at its opposite end.
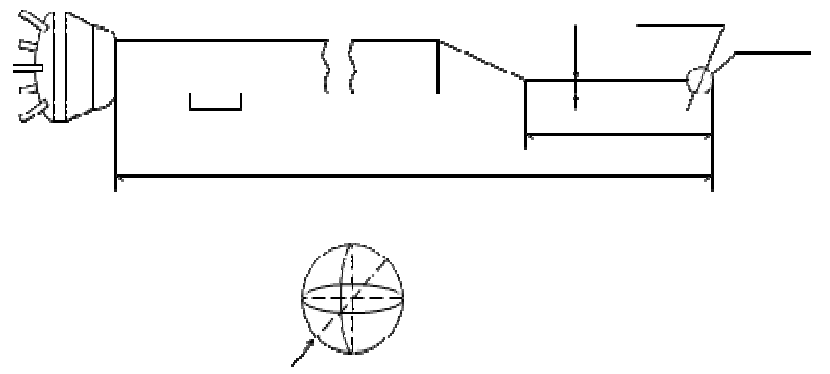

Fig.4. The scheme of ball probe

The head is attached to the side holder, which reduces the effect of the holder on the distribution of pressure on the surface of the sphere. For the same reasons, the variable diameter of the holder is adopted. Directly at the sphere it is equal to $1.8 \mathrm{~mm}$, and further increases to $6 \mathrm{~mm}$.

When the flow parameters were changed, the calibration was first carried out using a ball probe. The essence of calibration consists in determining the dependence on the angle of the dimensionless complexes $\mathrm{K}$; K3-K1; K2-K4; K2, 
which are calculated from the readings of micro manometers connected to the corresponding openings of the probe. In this case, a generally accepted measurement technique (9) was used, in which one of the angles characterizing the position of the averaged speed vector in the selected coordinate system $(\beta)$ is determined by rotating the probe about its axis until the pressure in the holes 5 and 4 is equalized, and the other $(\delta)$ using calibration curves, using the readings of differential micro manometers connected to the probe holes. Further, according to the calibration curves, the value of the averaged velocity and static pressure in the investigated point of flow is determined by the formulas:

$$
\begin{gathered}
V=\frac{2}{\rho} \cdot \frac{P_{2}-P_{4}}{K_{2}-K_{4}} \\
P_{1}-P_{a}=P_{2}-K_{2} \cdot \frac{P_{2}-K_{4}}{K_{2}-K_{4}} .
\end{gathered}
$$

If the coordinate system is chosen so that its origin coincides with the center of the probe ball and the coordinate axes are directed as shown in Fig. 3, then we obtain the following expressions for the component of the averaged velocity:

$$
\begin{gathered}
U_{x}=U \cdot \cos \delta \cdot \cos \beta U_{r}=U \cdot \sin \delta \\
U=U \cdot \cos \delta \cdot \sin \beta .
\end{gathered}
$$

The measurement error was $2.5-0.8 \%$ :

$$
\delta_{m}= \pm \frac{1}{2} \cdot\left[\frac{\Delta \mathrm{P}}{\mathrm{P}}+\delta_{t}+\delta \cdot \gamma_{t}+\delta \cdot \gamma_{\text {air }}\right]
$$

The results obtained were compared with the velocities measured by the thermo anemometer. The method of the thermo anemometer is based on the dependence of the heat transfer of a thin heated filament placed in the flow on the flow velocity over its stream. Thermo-anemometer sensors are small in size and introduce small perturbations into the flow. The lower limit of the measured velocities for a thermo anemometer under ordinary conditions is tens of centimeters per second. The method of measuring by rotation of a single sensor is adopted using preliminary spatial calibrations. A thermo-anemometer of constant temperature $\mathrm{T}-1$ was used (Fig. 5).

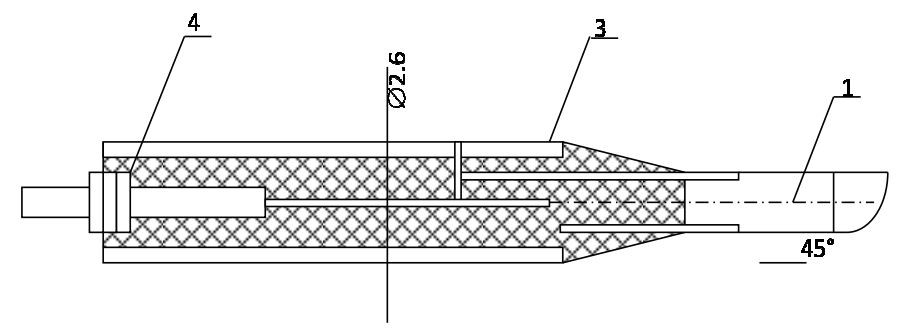

Fig.5. Scheme of thermo-anemometer sensor (1 - thread, 2 - ears, 3 - casing, 4 - connector)

The sensitive element of the thermo-anemometer sensor is a tungsten filament with a diameter of $7 \mathrm{~mm}$ and a length of 2 $\mathrm{mm}$. The body of the sensor is made of stainless tube with a diameter of $2.6 \mathrm{~mm}$. The thread holders (antennae) were made of nickel wire $0.5 \mathrm{~mm}$ in diameter, which were connected to the contacts of the sensor connector. To prevent accidental damage to the wires and impart rigidity to the antennae, the entire tube was filled with epoxy resin. After filling, the antennae were etched in a $50 \%$ solution of sulfuric acid to give them a needle-like shape.

The tungsten filament was attached to the antennae by contact welding perpendicular to the axis of the probe.

The probe was moved along the cross-section of the model (in the radial direction) by a coordinator providing a displacement accuracy of $0.05 \mathrm{~mm}$. Before the beginning of the experiment, the sensor was calibrated in a special smallsized wind tunnel.

The position of the sensor was set at the maximum of the voltmeter readings of the DC voltage. During calibration, a connection was established between the flow velocity flowing around the sensor and the voltage on the measuring diagonal of the thermo-anemometer bridge, which is recorded by a pointer device built into a hot anemometer and a voltmeter B723. The basic equation of a constant-temperature thermo anemometer is as follows:

$$
\mathrm{E}^{2}=\mathrm{E}_{0}^{2}+\mathrm{B} \cdot \mathrm{V}
$$

where

$\mathrm{E}$ - the value of the output voltage anemometer;

$\mathrm{V}$ - flow rate.

Coefficients $\mathrm{E}_{0}{ }^{2}$ and $\mathrm{B}$ were determined by fitting the experimental points' calibration curve.

In the experimental study, we measured the flow constant and variable components of the voltage output from the hotwire anemometer. The constant component of the voltage was measured with a voltmeter B7-34A through an integrating link, and the variable with a voltmeter $\Phi 563$. The electrical connection diagram of the measuring equipment is shown in Figure 6 . The value of the averaged speed was calculated by the formula:

$$
V=\frac{1}{2} \cdot\left(E^{2}-E_{0}^{2}\right)^{2}
$$

The value of the measurement error determined experimentally was 4\%. Figure 7 shows a comparison of profiles of the average velocity measured by a ball probe, a thermo anemometer and a full head tube. It can be seen that in most of the section, the experimental data agree well with each other.

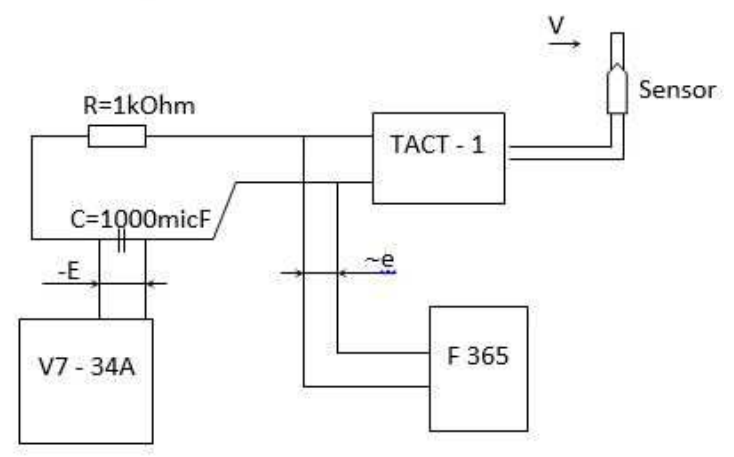

Fig.6. Connection diagram for measuring equipment 
Some discrepancy of the velocity profiles directly at the wall is due to the influence of the latter on the readings of the measuring nozzles.

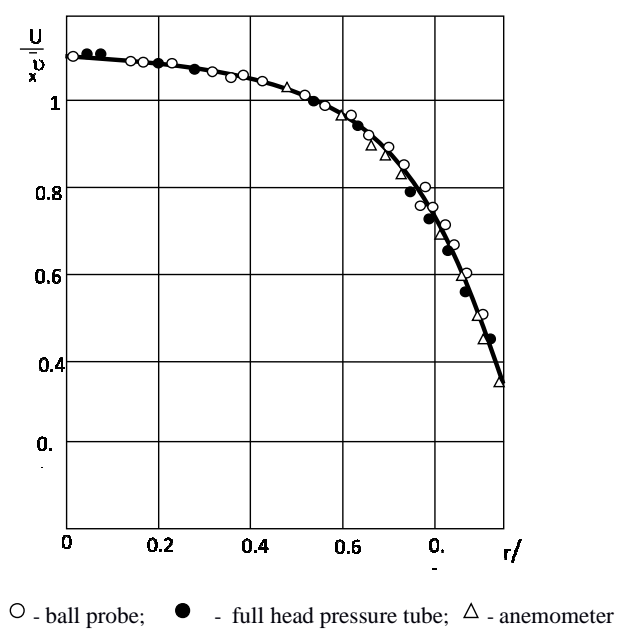

Fig.7. Average velocity profile

\section{CONCLUSions}

The hydrodynamic processes occurring in such devices and the influence of various factors on the flow regime were analyzed. A working section of the aerodynamic stand was developed and models that make it possible to investigate the flow by measuring the pressures, velocities, and resistance of the device were created.

\section{References}

[1] S.M. Gorlin, I.I. Slesinger, Aeromechanicheskie izmereniya (metody i pribory), Moscow: Nauka, 1964, pp. 720.

[2] N.K. Krasnovsky, Teoria upravleniem dvizheniya, Moscow: Nauka, 1968, pp. 325.
[3] V.I. Lukyanov, "Osobennosti gidrodinamiki zakruchennogo potoka vozduha v kolcevom kanale", Teplo I massa oben v letatelnyh apparatah, vol. 2, pp. 35-45, 1979.

[4] A. Erulanova, G. Shadrin, N. Arinova, "The study of the robust stability and quality of the two channel control system", pp. 1-4, 2016.[10th International Conference pp. 1-4, 2016].

[5] A. Erulanova, G. Shadrin, N. Arinova, I Asangaliiev, "Simulation of two-channel bulk materials metering system", InApplication of Information and Communication Technologies (AICT), October 14 2015[ 9th International Conference on 14 pp. 335-338, 2015 Oct].

[6] M. Mesarovic, D. Max, I. Takahara, Teoriya yerarhicheskih system, Moscow: Mir, 1973, pp. 458.

[7] G.I. Lapshenkov, L.M. Polotskiy, Avtomatizaciya proizvodstvennyh processov v himicheskoi promyshlennosti, Moscow: Chemistry, 1988, pp. 249.

[8] Shchukin V.K. Teploobmen i gidrodinamika vnutrennih potokov v polyah massovyh sil. Moscow: Mashinostroenie. 1980, pp. 240.

[9] B.V. Pankov, L.I. Frenkel, "O vozmozhnosti primeneniya trubki dlya izmereniya skorostey potokov", Trudy Tambovskogo Instituta mashinostroeniya. The Mabs, vol. 4, pp.360-364, 1970.

[10] I.A. Povkh, Aerodinamicheskie issledovaniya $\mathrm{v}$ mashinostroenii $-\mathrm{L}$.: Mechanical Engineering, pp.479, 1974.

[11] S.M. Gorlin, I.I. Slesinger, Aeromehanicheskie izmereniya, Moscow: Nauka, 1969, pp. 240.

[12] N. Surashev, M. V. Dudkin, D. Yelemes, A. Kalieva. The Planetary Vibroexciter with Elliptic Inner Race. Advanced Materials ResearchVols. 694-697 (2013), pp 229-232. Trans Publications, Switzerland. doi: 10.4028/ www.scientific.net/ AMR.694-697/229

[13] M. V. Doudkin, S.Yu. Pichugin, S.N. Fadeev. Studying the Machines for Road Maintenance. Life Science Journal 2013;10(12s):134-138. (ISSN:1097-8135). doi:10.7537/marslsj1012s13.24. http://www.lifesciencesite.com. 24

[14] M. V. Doudkin, A.V. Vavilov, S.Yu.Pichugin, S.N. Fadeev. Calculation of the Interaction of Working Body of Road Machine with the Surface. Life Science Journal 2013;10(12s):832-837]. (ISSN:10978135 doi:10.7537/marslsj1012s13.133. http://www.lifesciencesite.com. 133.

[15] A.Kim, M. V. Doudkin, A.Vavilov, G.Guryanov. New vibroscreen with additional feed elements. Archives of Civil and Mechanical Engineering, Volume 17, Issue 4, September 2017, Pages 786-794. () Politechnika Wrocławska. IF 2,19. https://doi.org/10.1016/j.acme.2017.02.009 